David M Colquhoun

MB BS, FRACP, FCSANZ,

Associate Professor of Medicine

Stephen J Bunker RN, PhD

Adjunct Senior Lecturer

David M Clarke PhD, FRACGP, FRANZCP, Professor, and Psychiatrist, Consultation-Liaison Psychiatry Service, Monash Medical Centre

Nick Glozie MB BS, FRANZCP PhD, Professor of Psychiatry

David L Hare DPM, FRACP, FCSANZ, Professor and Coordinato of Cardiovascular Research ${ }^{5}$

Ian B Hickie

MD, FRANZCP. FASSA

Professor of Psychiatry

James Tatoulis

MB BS, MD, FRACS Chief Medical Advisor

David R Thompson MA, PhD, FRCN Professor of Nursing

Geoffrey H Tofler MB BS, MD, FRACP, Professor of Preventive Cardiology ${ }^{8}$

Alison Wilson MBA,

National Manage Clinical Programs

Maree G Branagan

Project Office Clinical Programs

1 University of Queensland Brisbane, QLD.

2 Greater Green Triangle University Department of Rural Health and Flinders University, eakin University, Warrnambool, VIC.

3 School of Psychology and Psychiatry, Monash University, Melbourne, VIC

4 Brain and Mind Research Institute, University of Sydney,

Sydney, NSW.

5 Austin Hospital,

Melbourne, VIC

6 National Heart Foundation of Australia Melbourne, VIC.

7 Cardiovascular Research Centre Australian Catholic University, Melbourne, VIC.

8 Cardiology Department Royal North Shore Hospital, University of Sydney, Sydney, NSW.

maree.branagan@ heartfoundation.org.au

doi: 10.5694/mjal3.10153

\title{
Screening, referral and treatment for depression in patients with coronary heart disease
}

\author{
A consensus statement from the National Heart Foundation of Australia
}

n 2003, an Expert Working Group of the National Heart Foundation of Australia (NHFA) issued a position statement on the relationship between "stress" and heart disease. They concluded that depression was an important independent risk factor for first and recurrent coronary heart disease (CHD) events. ${ }^{1}$ Here, we provide an update on evidence obtained since 2003 regarding depression in patients with $\mathrm{CHD}$, and include guidance for health professionals on screening and treatment for depression in these patients. Our statement refers to depression in general (mild, moderate and severe), as all grades of depression have an impact on CHD prognosis. The process for developing this consensus statement is described in Box 1. Treatment decisions should take into account the individual clinical circumstances of each patient.

\section{Epidemiology}

The prevalence of depression is high in patients with CHD. Rates of major depressive disorder of around 15\% have been reported in patients after myocardial infarction (MI) or coronary artery bypass grafts., ${ }^{3,4}$ If milder forms of depression are included, a prevalence of greater than $40 \%$ has been documented. ${ }^{3,4}$ Recently, the EUROASPIRE III study investigated 8580 patients after hospitalisation for CHD. ${ }^{5}$ The proportion of patients with depression, measured by the Hospital Anxiety and Depression Scale, varied from $8.2 \%$ to $35.7 \%$ in men and $10.3 \%$ to $62.5 \%$ in women. This is consistent with Australian and New Zealand data from a 6-year study, Long-term Intervention with Pravastatin in Ischaemic Disease (LIPID). ${ }^{6,7}$ At the end of this trial, $27 \%$ of men and $35 \%$ of women were identified as depressed, using the Beck Depression Inventory II (BDI-II) questionnaire.

A large systematic review in 2006 suggested that individuals with depression, but no current $\mathrm{CHD}$, have a moderately elevated risk of 1.6 for a later index CHD event. ${ }^{8}$ This elevated risk was confirmed in the Whitehall II study of 5936 healthy individuals over a 6-year period, in which depression was associated with a hazard ratio of 1.93 for cardiovascular events. ${ }^{9}$ In the Nurses Health Study, 78282 healthy women were assessed for depression. In the 6-year follow-up period, 4654 deaths were reported, including 979 deaths from cardiovascular disease. ${ }^{10}$ Depression was associated with increased all-cause

\begin{abstract}
Summars
- In 2003, the National Heart Foundation of Australia position statement on "stress" and heart disease found that depression was an important risk factor for coronary heart disease (CHD). This 2013 statement updates the evidence on depression (mild, moderate and severe) in patients with $\mathrm{CHD}$, and provides guidance for health professionals on screening and treatment for depression in patients with $\mathrm{CHD}$.
\end{abstract}

- The prevalence of depression is high in patients with CHD and it has a significant impact on the patient's quality of life and adherence to therapy, and an independent effect on prognosis. Rates of major depressive disorder of around $15 \%$ have been reported in patients after myocardial infarction or coronary artery bypass grafting.

- To provide the best possible care, it is important to recognise depression in patients with $\mathrm{CHD}$. Routine screening for depression in all patients with $\mathrm{CHD}$ is indicated at first presentation, and again at the next follow-up appointment. A follow-up screen should occur 2-3 months after a CHD event. Screening should then be considered on a yearly basis, as for any other major risk factor for CHD.

- A simple tool for initial screening, such as the Patient Health Questionnaire-2 (PHQ-2) or the short-form Cardiac Depression Scale (CDS), can be incorporated into usual clinical practice with minimum interference, and may increase uptake of screening.

- Patients with positive screening results may need further evaluation. Appropriate treatment should be commenced, and the patient monitored. If screening is followed by comprehensive care, depression outcomes are likely to be improved.

- Patients with CHD and depression respond to cognitive behaviour therapy, collaborative care, exercise and some drug therapies in a similar way to the general population. However, tricyclic antidepressant drugs may worsen CHD outcomes and should be avoided.

- Coordination of care between health care providers is essential for optimal outcomes for patients. The benefits of treating depression include improved quality of life, improved adherence to other therapies and, potentially, improved CHD outcomes.

mortality, with an age-adjusted relative risk of 1.76 (95\% CI, 1.64-1.89). ${ }^{10}$ The effect of depression on CHD incidence is thought to be strongest around the time of the depressive episode, with longer-term effects mediated via 


\section{Process used to develop this National Heart Foundation of} Australia consensus statement

The Expert Working Group members performed relevant literature searches using key search phrases including, but not limited to, "stress", "depression", "anxiety", "treatment of depression", "acute coronary syndromes", "adherence and depression" and "screening for depression". This was complemented by reference lists compiled from reviews and personal collections of the Expert Writing Group members. Searches were limited to evidence available for human subjects with coronary heart disease published in English up to December 2012. The recommendations made in this consensus statement have been graded according to the National Health and Medical Research Council guidelines (see Appendix). ${ }^{2}$ The Cardiac Society of Australia and New Zealand, beyondblue: the national depression initiative and the Royal Australian and New Zealand College of Psychiatrists were consulted during the development of this document and have endorsed its content.

recurrence of depression. ${ }^{11}$ In young people the association between depression and CHD may be stronger. ${ }^{12}$

The case-control INTERHEART Study included 11119 patients with MI from 52 countries. ${ }^{13}$ Perceived stress and depression were shown to be important risk factors, which together accounted for $32.5 \%$ of the population attributable risk (PAR) for $\mathrm{CHD}$, suggesting that together they were as important as smoking and more important than diabetes (PAR, 9.9\%) and hypertension (PAR, 17.9\%) as risk factors for CHD. ${ }^{13}$

For people with $\mathrm{CHD}$ and comorbid depression, the relative risk (RR) of death is increased (RR, 1.80 [95\% CI, 1.50-2.15]), independent of standard risk factors for secondary prevention. ${ }^{8}$ Comorbid depression also leads to a higher risk of other adverse outcomes in patients with CHD, such as a lower likelihood of return to work, poorer exercise tolerance, less adherence to therapy, greater disability, poorer quality of life, cognitive decline and earlier dependency. ${ }^{14-20}$ Individuals with CHD and comorbid depression often have less access to interventions for CHD, despite being in a higher-risk group. ${ }^{21-23}$

\section{Definition of depression and types of depression}

The diagnosis of depression can be difficult in people with cardiovascular disease, as depressive symptoms such as fatigue and low energy are common to both CHD and heart failure, and may also be a side effect of some drugs used to treat cardiovascular disease, such as $\beta$-blockers. ${ }^{24}$ The diagnosis may be further complicated in such patients by their responses to their disease (and the associated stigma), which may include denial, avoidance, withdrawal and anxiety.

According to the Diagnostic and statistical manual of mental disorders, fourth edition (DSM-IV), ${ }^{25}$ major depression is diagnosed when there is a minimum of 2 weeks of depressed mood and/or lack of pleasure (anhedonia), accompanied by four or more other (listed) symptoms such as sleep disturbance, appetite disturbance, poor energy, psychomotor impairment or agitation, poor concentration or poor decision making, and suicidal ideas or thoughts of death. The association with CHD appears to increase with greater severity of depressive symptoms across the spectrum, with no discrete cut-off point at "major depression".
Some studies have suggested links between particular subtypes of depression, such as somatic or anhedonic depression, but these are not consistent findings. ${ }^{26-28}$

\section{Screening for depression in patients with} coronary heart disease

Screening of a population group for a risk factor or disease is worthwhile when the risk factor or disease has a reasonably high prevalence, there is a robust screening test, and effective and cost-effective treatments are readily available. ${ }^{29,30}$ Depression is both a risk factor and a disease in its own right, and fulfils these criteria for population screening. Screening for depression in patients with CHD would be expected to produce a higher yield than screening for depression in the general population, owing to a much higher prevalence of depression in patients with CHD. It is important to recognise depression in patients with $\mathrm{CHD}$ in order to provide the best possible care. Asymptomatic patients with significant cardiovascular risk factors (eg, those with diabetes) may also be considered for screening, as they have a high risk of depression. ${ }^{31}$

Many self-reported screening tools exist with the aim of detecting possible depression. These include the Patient Health Questionnaire (PHQ-2, PHQ-9), the Cardiac Depression Scale (CDS), the BDI-I and -II, and the Hospital Anxiety and Depression Scale. ${ }^{32,33}$ The BDI appears to be the most commonly used tool in studies involving cardiac patients. The CDS was developed by a member of the Expert Working Group (D L H) specifically for patients with cardiac disease. ${ }^{33}$ The short version (short form) has only five items. There is limited but expanding information on the use of the PHQ-9 in patients with cardiac disease. $^{34,35}$ It is used widely in primary care. Simple tools such as the Kessler Psychological Distress Scale (K10), ${ }^{36}$ a measure of general distress, will often overdiagnose depression. This tool is currently used in mental health plans in Australia; however, there is no evidence of its use specifically for patients with CHD.

Recognising the need for a simple screening tool for depression in cardiovascular patients, the 2008 American Heart Association (AHA) Science Advisory suggested the use of the PHQ-2. ${ }^{37}$ The PHQ-2 is an abbreviated form of the PHQ-9, with only the first two of the nine questions in the PHQ-9 (Box 2). ${ }^{38}$ There are also other versions of the PHQ-2, which may use shorter time frames. The AHA recommended the use of the PHQ-9 if depression was noted using the PHQ-2. ${ }^{37}$ The Royal Australian College of General Practitioners' Guidelines for preventive activities in general practice (the red book) also uses a categorical (Yes/ $\mathrm{No})$ version of the PHQ-2. ${ }^{39}$

The PHQ-2 and the PHQ-9 screening tools are associated with reasonable sensitivity and specificity. ${ }^{34}$ Importantly, depression diagnosed with the PHQ-2 and the

\footnotetext{
2 Patient Health Questionnaire (PHQ-2) Yes/No version ${ }^{35}$

During the past month, have you often been bothered by feeling down, depressed or hopeless?

During the past month, have you often been bothered by little interest or pleasure in doing things?
} 
PHQ-9 has been shown to predict worse CHD outcomes. In the Heart and Soul Study, positive responses to either question in the PHQ-2 (Yes/No version) predicted a 55\% greater risk of cardiovascular events. ${ }^{35}$ Furthermore, the validity of the PHQ-2 and the PHQ-9 has been assessed in a variety of patients with varying clinical problems, ages and ethnicities, including in Australian Aboriginal people from urban and rural areas and people from the Torres Strait Islands. ${ }^{40-42}$ Adapted versions exist for use with Indigenous people.

Access to each of the tools varies. No copyright is breached by use of the PHQ-2 and the PHQ-9, and the PHQs and the CDS are free. ${ }^{43}$ However, some questionnaires such as the BDI-I and -II are subject to copyright and a royalty must be paid each time they are used. ${ }^{44}$

Implicit in the AHA Science Advisory ${ }^{37}$ is that screening and identification of patients with depression leads to appropriate treatment, or referral for treatment, by the responsible attending medical practitioner. Unfortunately, research has shown that screening may have little or no impact on the treatment of depression or on outcomes. ${ }^{45,46}$ Screening by nurses, researchers, receptionists or social workers is not sufficient without appropriate referral or treatment.

It is recommended that a simple tool, such as the PHQ2 or the short-form CDS, is incorporated into routine screening of patients with CHD. Routine screening for depression is indicated at first presentation, and again at the next follow-up appointment. A follow-up screen should occur 2-3 months after a CHD event. Screening should then be considered on a yearly basis, as for any other major risk factor for CHD. Consideration should also be given to screening the partner or spouse of these patients for depression, as studies show that they are at an increased risk of developing depression. ${ }^{47}$ If screening is followed by comprehensive care, depression outcomes are likely to be improved.

\section{Treatment of depression in patients with CHD}

\section{Collaborative care}

Although individual treatment approaches and strategies have been studied, in practice a collaborative-care or stepped-care approach is probably optimal for managing patients with CHD and comorbid depression. The concept of collaborative care involves a group of health professionals working together in a coordinated manner, and this approach has consistently been shown to be associated with greater improvement in depression for patients with CHD compared with standard care, and to be cost-effective. ${ }^{48-52}$ For example, collaborative care after coronary artery bypass grafting improved depression scores, but not physical function or re-hospitalisation rates. ${ }^{48}$ In patients with depression comorbid with poorly controlled diabetes and/or CHD, the collaborative approach resulted in improvement in depression scores, glycated haemoglobin levels, low-density lipoprotein cholesterol levels, and systolic blood pressure. ${ }^{50}$

The Coronary Psychosocial Evaluation Studies (COPES) trial $^{52,53}$ used a stepped-care treatment approach in patients with acute coronary syndromes (ACS) and persistent depression. Depressive symptoms decreased substantially in the intervention (stepped-care) group. Only three $(4 \%)$ of the intervention patients experienced major adverse cardiac events compared with 10 (13\%) of the patients given usual care, suggesting improved cardiovascular outcomes. Moreover, this stepped-care approach was associated with a $43 \%$ lower total health cost over the 6 month trial period. ${ }^{54}$

\section{Pharmacological therapy}

The efficacies of fluoxetine, ${ }^{55}$ sertraline (Sertraline Antidepressant Heart Attack Randomized Trial [SADHART], ${ }^{56}$ Enhancing Recovery in Coronary Heart Disease Patients [ENRICHD] trial), ${ }^{57}$ citalopram (Cardiac Randomized Evaluation of Antidepressant and Psychotherapy Efficacy trial [CREATE] $)^{58}$ and mirtazapine (Myocardial Infarction and Depression Intervention Trial [MIND-IT] $)^{59}$ have been evaluated in clinical trials involving patients with CHD.

SADHART studied depression after ACS over 6 months. Depression scores in patients taking sertraline improved significantly more than in those receiving placebo. Most patients were also prescribed aspirin, statins and $\beta$-blockers. Life-threatening cardiovascular events occurred less frequently in the sertraline group; however, this result was not statistically significant. ${ }^{56}$

ENRICHD was a large trial that evaluated the effect of cognitive behaviour therapy (CBT) on depression or low social support in patients with a recent MI. Depression was diagnosed in $74 \%$ of participants. CBT improved depression but failed to reduce the number of CHD events. Patients whose depression did not respond to CBT were referred for treatment with antidepressant drugs. Selective serotonin reuptake inhibitors (SSRIs) (mainly sertraline) significantly improved depression in those patients. In the SSRI-treated group, there was a $43 \%(P<0.005)$ reduction in deaths or recurrent MIs. ${ }^{57}$ However, this was a subset analysis, and therefore is hypothesis generating only.

In the Canadian CREATE trial $^{58}$ and the MIND-IT trial, ${ }^{59}$ there were too few CHD events reported to enable analysis of cardiovascular outcomes.

Tricyclic antidepressants may worsen CHD outcomes and should be avoided in patients with CHD. Importantly, tricyclic antidepressants have been associated with increased mortality in patients with CHD. ${ }^{60-62}$ In contrast, a recent meta-analysis of trials involving SSRIs in patients with CHD concluded that this class of drugs was well tolerated, with the risk of adverse events being similar to that for placebo. ${ }^{63}$

\section{Psychological therapy}

Of the various psychological therapies, CBT and integrative therapies (eg, interpersonal psychotherapy) have the best documented efficacy for treatment of major depressive disorder. ${ }^{64,65}$ CBT was used in the ENRICHD trial, ${ }^{57}$ interpersonal psychotherapy in the CREATE trial, ${ }^{58}$ and problem-solving therapy in the COPES trial. ${ }^{52,53}$ These therapies were all beneficial for depression but did not affect CHD outcomes. The efficacy of psychological therapy as a treatment for major or minor depression was evaluated in patients who underwent coronary artery 
bypass surgery. ${ }^{66}$ Significantly more patients in the CBT group $(71 \%)$ and the stress management group (57\%) had low depressive symptom levels, compared with those having usual care (33\%), and these results were maintained at 6 months. ${ }^{66}$

A Cochrane review of psychological interventions for patients with CHD found evidence of small-to-moderate improvements in depression and anxiety symptoms with such interventions, but no strong evidence that the interventions reduced total deaths, risk of revascularisation, or non-fatal infarction. ${ }^{67}$ The interventions that were less effective were those that aimed to educate patients about cardiac risk factors; those that included client-led discussion and emotional support; or those that included family members in the treatment process. ${ }^{67}$ Uncertainty remains regarding the subgroups of patients who would benefit most from psychological treatments and the characteristics of successful interventions.

\section{Exercise}

Many patients with mild depression respond well to regular exercise and cardiac rehabilitation (exercise-based). A recent Cochrane review of exercise as a treatment for depression concluded that exercise improves depression with a similar efficacy to CBT. ${ }^{68}$ The benefit of exercise appears to have a dose-response relationship, needing at least 30 minutes of moderate aerobic activity on 5 days per week. ${ }^{69,70}$ This is consistent with usual public health recommendations.

The benefit of exercise in patients with CHD and depression has been demonstrated in the recent UPBEAT (Understanding the Prognostic Benefits of Exercise and Antidepressant Therapy) trial. ${ }^{71}$ Patients with $\mathrm{CHD}$ with at least a mildly elevated score for depressive symptoms (BDI score $>7$ ) were allocated at random to treatment with SSRIs, exercise or neither. Exercise was equivalent to SSRI treatment in improving depression scores, with patients in both groups showing greater improvement than the control group. ${ }^{71}$ In a large randomised controlled trial (RCT) of 2322 patients with heart failure (of whom 28\% were depressed), exercise, in addition to reducing mortality and hospitalisation $(P=0.03)$, significantly reduced depression $(P=0.002) .^{72}$

\section{Complementary and alternative therapies}

Up to $50 \%$ of patients with depression have been shown to use complementary and alternative medicines without disclosing this to their treating clinician. ${ }^{73}$ Therapies that may be effective in depression are supplemental marine n3 fatty acids (eicosapentaenoic acid [EPA] and docosahexaenoic acid [DHA]), S-adenosylmethionine (SAMe) and St John's wort. ${ }^{74}$ Specific trials in patients with CHD and depression have not been performed with the latter two therapies.

Marine n-3 fatty acids (at a dose of $1 \mathrm{~g}$ per day of combined EPA-DHA) are recommended by the NHFA and the AHA for all patients with CHD. ${ }^{75}$ This dose also may improve mild depression. However, the addition of $2 \mathrm{~g} /$ day of combined EPA and DHA to sertraline $50 \mathrm{mg}$ daily for depressive symptoms appears to provide no added benefit over sertraline alone. ${ }^{76}$ Some trials compar- ing St John's wort and SAMe to antidepressant medications suggest a similar effectiveness in improving depression to antidepressant medications. ${ }^{77-79}$ However, most commercial brands of St John's wort have not undergone randomised trials. ${ }^{78,79}$

\section{Adherence}

Depression is a major predictor of poor adherence in patients with $\mathrm{CHD}$, be it to drug therapy or lifestyle measures. ${ }^{80,81}$ Patients with depression are three times more likely to be non-compliant with medical treatment than patients without depression. ${ }^{82}$ Greater severity and chronicity of depression have been associated with poorer adherence to aspirin therapy after MI. ${ }^{83}$ Adherence to aspirin therapy after ACS has been shown to be significantly lower in persistently depressed patients $(76.1 \%)$ than in those whose depression improved $(87.4 \%)$, or who were not depressed (89.5\%). ${ }^{83}$ Patients who are persistently depressed are also less likely to undertake behaviours that reduce risk; for example, quitting smoking, taking medications, exercising and attending cardiac rehabilitation. ${ }^{81}$ The SADHART trial showed adherence to medication increased after remission of depression in $68.4 \%$ of participants taking the trial medication. ${ }^{84}$

A recent RCT of a collaborative-care depression treatment program in 134 patients with depression after ACS demonstrated improved adherence to medications and secondary prevention behaviours and was independently associated with improvement in depression. ${ }^{85}$ However, in another RCT of 157 patients undergoing treatment for depression after ACS, there were no improvements in adherence to risk-reducing behaviours in spite of a significant reduction in depression. ${ }^{86}$

\section{Referral}

Once depression is identified through screening, treatment may be initiated immediately, or referral to psychological or psychiatric services may also be considered appropriate. Most patients with depression in Australia are managed by general practitioners. ${ }^{87}$

Members of the Cardiac Society of Australia and New Zealand, the majority of whom are clinical cardiologists, were surveyed regarding assessment of depression. Most respondents screened for depression occasionally, with only 3\% using a formal tool. Lack of confidence in identifying depression was the strongest predictor of a low screening frequency. Cardiologists rarely initiated treatment for depression, and $43 \%$ did not feel they were responsible for treating depression. ${ }^{88}$

There can be a reluctance to treat depression in patients with CHD because of a belief that depression is normal after an acute cardiovascular event. Mild depression may resolve spontaneously; however, for most individuals with $\mathrm{CHD}$, depression remains long term. ${ }^{89}$

\section{Conclusion}

A summary of the key evidence-based points is provided in Box 3 and Box 4, and the Appendix gives the National 
3 National Heart Foundation of Australia grades of recommendation and levels of evidence for screening, referral and treatment for depression in patients with coronary heart disease (CHD) ${ }^{2}$

Recommendation

Grade $^{2} \quad$ Level $^{2}$

1 For patients with CHD, it is reasonable to screen for depression

\begin{tabular}{|c|c|}
\hline A & 1 \\
\hline A & 1 \\
\hline D & II \\
\hline B & III-2 \\
\hline A & I \\
\hline B & II \\
\hline B & II \\
\hline D & II \\
\hline A & 1 \\
\hline D & || $\mid-1$ \\
\hline B & $\|$ \\
\hline D & $\|$ \\
\hline
\end{tabular}

SSRIS = selective serotonin reuptake inhibitors .

$\bullet$

4 Treatment of depression in patients with coronary heart disease (CHD) - summary of treatment subgroup effects showing grade of recommendation and level of evidence

\begin{tabular}{|c|c|c|c|c|}
\hline \multirow[b]{2}{*}{ Treatment } & \multicolumn{2}{|c|}{ Depression } & \multicolumn{2}{|c|}{ CHD outcome } \\
\hline & Grade $^{2}$ & Level $^{2}$ & Grade $^{2}$ & Level $^{2}$ \\
\hline \multicolumn{5}{|l|}{ Non-drug } \\
\hline Exercise & $A$ & । & B & ॥ \\
\hline $\begin{array}{l}\text { Psychological, } \\
\text { including CBT }\end{array}$ & B & ॥ & D & ॥ \\
\hline St John's wort* & $D$ & -* $^{*}$ & D & $-^{*}$ \\
\hline n-3 fatty acids & $D$ & ॥ & $\mathrm{D}^{\dagger}$ & ॥ \\
\hline SAMe* & $D$ & $-^{*}$ & $D$ & $-*$ \\
\hline Collaborative & B & ॥ & D & ॥ \\
\hline \multicolumn{5}{|l|}{ Drug } \\
\hline SSRIs & A & I & D & III-1 \\
\hline
\end{tabular}

$\mathrm{CBT}=$ cognitive behaviour therapy. SAMe = S-adenosylmethionine. SSRIS = selective serotonin reuptake inhibitors. * Insufficient evidence to rate or no trials have been performed. † Data not available in patients with CHD.

Health and Medical Research Council grades of recommendations and evidence hierarchy.

High-quality care for treatment of depression is achievable and affordable. The benefits of treating depression in people with CHD include improved quality of life, improved adherence to other therapies and potentially improved CHD outcomes. ${ }^{90}$ Effective treatment of depression may decrease $\mathrm{CHD}$ events but this is not proven, as no adequately powered trials have been completed, nor are there any ongoing.

Acknowledgements: We thank Brian Oldenburg, Adrienne O’Neil, Michael Jelinek and Alex Brown for their consultation and contribution to the content of this document. Competing interests: David Colquhoun has been a member of advisory groups for industry including for MSD, Pfizer (Lipid advisory group), Abbott (Fish oil advisory group). He has undertaken research for Boehringer Ingelheim (RELY trial), Abbott (SCOUT trial), BMS (SAVOR trial), and for Sanofi-Aventis (PALLAS Trial and ORIGIN Trial). He is also a member of the Gallipoli Research Foundation Scientific Committee. David Hare

developed the CDS, and has received research, fellowship and consultancy funds from the NHMRC, the NHFA, the Austin Medical Research Foundation, beyondblue, and Diabetes Australia. He has received payment for research projects, consultancies, travel, advisory board memberships and lectures from industry including Abbott, Amgen, AstraZeneca,
Biotronic, BMS, Boehringer Ingelheim, CSL-Biotherapies, Hoffmann-LaRoche, Hospira, Lundbeck (Denmark), Medtronic, Menarini, Merck KA (Germany), Merck (US), MSD, Pfizer, Roche, Sanofi-Aventis, Servier and Wyeth. Ian Hickie was supported by an NHMRC Australia Fellowship (No. 464914). He was a director of headspace: the national youth mental health foundation until January 2012. He is the executive director of the Brain and Mind Research Institute, which operates two early intervention youth services under contract to headspace. He is a member of the new Australian National Mental Health Commission and was previously the CEO of beyondblue. He has led a range of community-based and pharmaceutical industry-supported depression awareness and education and training programs, and depression and other mental health research projects supported by a variety of pharmaceutical partners. His current investigatorinitiated studies are supported by Servier and Pfizer. He has received honoraria for his contributions to professional educational seminars supported by the pharmaceutical industry (including Servier, Pfizer, AstraZeneca, Janssen and Eli Lilly). Nick Glozier has been funded under a strategic research grant program by beyondblue and the NHFA. He has received other depression-related research funds from the NHMRC, beyondblue, the Australian Research Council and Servier Laboratories. He has received travel and consultancy fees from Servier Laboratories. There are no relevant disclosures for the other authors.

Provenance: Not commissioned; externally peer reviewed.

1 Bunker SJ, Colquhoun DM, Esler MD, et al. "Stress" and coronary heart disease: psychosocial risk factors. Med J Aust 2003; 178: 272-276.

2 National Health and Medical Research Council. NHMRC additional levels of evidence and grades for recommendations for developers of guidelines. December 2009. https://www.nhmrc.gov.au/_files_nhmrc/file/guidelines/ developers/nhmrc_levels_grades_evidence_120423.pdf (accessed Aug 2012).

3 Thombs BD, Bass EB, Ford DE, et al. Prevalence of depression in survivors of acute myocardial infarction. J Gen Intern Med 2006; 21: 30-38.

4 Carney RM, Freedland KE. Depression, mortality, and medical morbidity in patients with coronary heart disease. Biol Psychiatry 2003; 54: 241-247.

5 Cooney MT, Kotseva K, Dudina A, et al. Determinants of risk factor control in subjects with coronary heart disease: a report from the EUROASPIRE III investigators. Eur J Prev Cardiol 2012; Apr 18.

6 Stewart RA, North FM, West TM, et al; Long-term Intervention with Pravastatin in Ischaemic Disease (LIPID) study investigators. Depression and cardiovascular morbidity and mortality: cause or consequence? Eur Heart J 2003; 24: 2027-2037.

7 Weyers J, Colquhoun D, Stewart R, et al; for the LIPID study group. Prevalence of depression in patients with coronary heart disease (CHD) on cholesterol lowering therapy with pravastatin. Abstracts of the XIlth International Symposium on Atherosclerosis; 2000 Jun 25-29; Stockholm, Sweden. Atherosclerosis 2000; 151: 1-354.

8 Nicholson A, Kuper H, Hemingway H. Depression as an aetiologic and prognostic factor in coronary heart disease: a meta-analysis of 6362 events among 146538 participants in 54 observational studies. Eur Heart J 2006; 27: 2763-2774

9 Nabi H, Shipley MJ, Vahtera J, et al. Effects of depressive symptoms and coronary heart disease and their interactive associations on mortality in middle-aged adults: the Whitehall II cohort study. Heart 2010; 96: 1645-1650.

10 Pan A, Lucas M, Sun Q, et al. Increased mortality risk in women with depression and diabetes mellitus. Arch Gen Psychiatry 2011; 68: 42-50.

11 Kendler KS, Gardner CO, Fiske A, Gatz M. Major depression and coronary artery disease in the Swedish twin registry: phenotypic, genetic, and environmental sources of comorbidity. Arch Gen Psychiatry 2009; 66: 857-863.

12 Shah AJ, Veledar E, Hong Y, et al. Depression and history of attempted suicide as risk factors for heart disease mortality in young individuals. Arch Gen Psychiatry 2011; 68: 1135-1142.

13 Yusuf S, Hawken S, Ounpuu S, et al. INTERHEART Study Investigators. Effect of potentially modifiable risk factors associated with myocardial infarction in 52 countries (the INTERHEART study): case-control study. Lancet 2004; 364 : 937-952.

14 O'Neil A, Sanderson K, Oldenburg B. Depression as a predictor of work resumption following myocardial infarction (MI): a review of recent research evidence. Health Qual Life Outcomes 2010; 8: 95

15 Frasure-Smith N, Lespérance F. Depression and anxiety as predictors of 2-year cardiac events in patients with stable coronary artery disease. Arch Gen Psychiatry 2008; 65: 62-71.

16 Moussavi S, Chatterji S, Verdes E, et al. Depression, chronic diseases, and decrements in health: results from the World Health Surveys. Lancet 2007; 370: 851-858.

17 Naismith S, Glozier N, Burke D, et al. Early intervention for cognitive decline: is there a role for multiple medical or behavioural interventions? Early Interv Psychiatry 2009; 3: 19-27.

18 Ruo B, Rumsfeld JS, Pipkin S, Whooley MA. Relation between depressive symptoms and treadmill exercise capacity in the Heart and Soul study. Am J Cardiol 2004; 94: 96-99.

19 Mallik S, Krumholz HM, Lin ZQ, et al. Patients with depressive symptoms have lower health status benefits after coronary artery bypass surgery. Circulation 2005; 111: 271-277.

20 Larsen KK, Agerbo E, Christensen B, et al. Myocardial infarction and risk of suicide: a population-based case-control study. Circulation 2010; 122: 2388-2393. 
21 Mitchell AJ, Lawrence D. Revascularisation and mortality rates following acute coronary syndromes in people with severe mental illness: comparative metaanalysis. Br J Psychiatry 2011; 198: 434-441.

22 National Institute for Health and Clinical Excellence (NICE). Depression in adults with a chronic physical health problem. NICE clinical guideline 91. October 2009. http://www.nice.org.uk/nicemedia/live/12327/45909/45909 (accessed Apr 2013).

23 Kiseley S, Smith M, Lawrence D, et al. Inequitable access for mentally ill patients to some medically necessary procedures. CMAJ 2007; 176: 779-784.

24 Whooley MA, Simon GE. Managing depression in medical outpatients. NEngl J Med 2000; 343:1942-1950.

25 American Psychiatric Association. Diagnostic and statistical manual of mental disorders (DSM-IV-TR), 4th edition. Washington, DC: APA, 2000.

26 Leroy M, Loas G, Perez-Diaz F. Anhedonia as predictor of clinical events after acute coronary syndromes: a 3-year prospective study. Compr Psychiatry 2010; 51: 8-14.

27 Pedersen SS, Denollet J, Daemen J, et al. Fatigue, depressive symptoms, and hopelessness as predictors of adverse clinical events following percutaneous coronary intervention with paclitaxel-eluting stents. J Psychosom Res 2007; 62: 455-461.

28 Tindle HA, Chang YF, Kuller LH, et al. Optimism, cynical hostility, and incident coronary heart disease and mortality in the Women's Health Initiative. Circulation 2009; 120: 656-662.

29 Mant D, Fowler G. Mass screening: theory and ethics. BMJ 1990; 300: 916-918.

30 Gilbody S, Sheldon T, Wessely S. Should we screen for depression? BMJ 2006; 332: 1027-1030.

31 Egede LE, Ellis C. Diabetes and depression: global perspectives. Diabetes Res Clin Pract 2010; 87: 302-312.

32 Thombs BD, de Jonge P, Coyne JC, et al. Depression screening and patient outcomes in cardiovascular care: a systematic review. JAMA 2008; 300: 2161-2171.

33 Hare DL, Davis CR. Cardiac depression scale: validation of a new depression scale for cardiac patients. J Psychosom Res 1996; 40: 379-386.

34 McManus D, Pipkin SS, Whooley MA. Screening for depression in patients with coronary heart disease (data from the Heart and Soul Study). Am J Cardiol 2005; 96: 1076-1081.

35 Elderon L, Smolderen K, Na B, Whooley MA. Accuracy and prognostic value of AHA-recommended depression screening in patients with coronary heart disease. Data from the Heart and Soul Study. Circ Cardiovasc Qual Outcomes 2011; 4: 533-540.

36 Kessler RC, Andrews G, Colpe LJ, et al. Short screening scales to monitor population prevalences and trends in non-specific psychological distress. Psychol Med 2002; 32: 959-976.

37 Lichtman JH, Bigger JT Jr, Blumenthal JA, et al. Depression and coronary heart disease: recommendations for screening, referral and treatment: a science advisory from the American Heart Association Prevention Committee of the Council on Cardiovascular Nursing, Council on Clinical Cardiology, Council on Epidemiology and Prevention, and Interdisciplinary Council on Quality of Care and Outcomes Research: endorsed by the American Psychiatric Association. Circulation 2008; 118: 1768-1775.

38 Whooley MA, Avins AL, Miranda J, Browner WS. Case-finding instruments for depression: two questions are as good as many. J Gen Intern Med 1997; 12: 439-445.

39 The Royal Australian College of General Practitioners. Guidelines for preventive activities in general practice. 7th edition, Chapter 10. Melbourne: RACGP, 2009: 59.

40 Esler D, Johnston F, Thomas D, David B. The validity of a depression screening tool modified for use with Aboriginal and Torres Strait Islander people. Aust NZ J Public Health 2008; 32: 317-321.

41 Esler DM, Johnston F, Thomas D. The acceptability of a depression screening tool in an urban, Aboriginal community-controlled health service. Aust NZ J Public Health 2007; 31: 259-263.

42 Poongothai S, Pradeepa R, Ganesan A, Mohan V. Reliability and validity of a modified PHQ-9 item inventory (PHQ-12) as a screening instrument for assessing depression in Asian Indians (CURES-65). J Assoc Physicians India 2009; 57: 147-152.

43 Pfizer. Patient Health Questionnaire (PHQ) screeners. http://www. phqscreeners.com/ (accessed Nov 2012).

44 Beck AT, Steer RA, Brown GK. Manual for the Beck Depression Inventory-II. 2nd edition. San Antonio, Tex: Psychological Corporation, 1996.

45 Dowrick C, Buchan I. Twelve month outcome of depression in general practice; does detection or disclosure make a difference? BMJ 1995; 311: 1274-1276.

46 Wells KA, Sherbourne C, Schoenbaum M, et al. Impact of disseminating quality improvement programmes for depression in managed primary care; a randomized controlled trial. JAMA 2000; 283: 212-220.

47 Fosbøl EL, Peterson ED, Weeke P, et al. Spousal depression, anxiety, and suicide after myocardial infarction. Eur Heart J 201 2013; 34: 649-656.

48 Rollman BL, Belnap BH, LeMenager MS, et al. Telephone-delivered collaborative care for treating post-CABG depression: a randomized controlled trial. JAMA 2009; 302: 2095-2103.
49 Huffman JC, Mastromauro CA, Sowden G, et al. Impact of a depression care management program for hospitalized cardiac patients. Circ Cardiovasc Qual Outcomes 2011; 4: 198-205.

50 Katon WJ, Lin EH, Von Korff M, et al. Collaborative care for patients with depression and chronic illnesses. N Engl J Med 2010; 363: 2611-2620.

51 Katon W, Russo J, Lin EH, et al. Cost-effectiveness of a multicondition collaborative care intervention: a randomized controlled trial. Arch Gen Psychiatry 2012; 69: 506-514.

52 Davidson KW, Rieckmann N, Clemow L, et al. Enhanced depression care for patients with acute coronary syndrome and persistent depressive symptoms: Coronary Psychosocial Evaluation Studies randomized controlled trial. Arch Intern Med 2010; 170: 600-608.

53 Burg MM, Lespérance F, Rieckmann N, et al. Treating persistent depressive symptoms in post-ACS patients: the project COPES phase-I randomised controlled trial. Contemp Clin Trials 2008; 29: 231-240.

54 Ladapo JA, Shaffer JA, Fang Y, et al. Cost-effectiveness of enhanced depression care after acute coronary syndrome: results from the Coronary Pychosocial Evaluation Studies randomized controlled trial. Arch Intern Med 2012; 172: 1682-1684.

55 Strik J, Honig A, Lousberg R, et al. Efficacy and safety of fluoxetine in the treatment of patients with major depression after first myocardial infarction: findings from a double-blind, placebo-controlled trial. Psychosom Med 2000; 62: 783-789.

56 Glassman AH, O'Connor CM, Califf RM, et al; Sertraline Antidepressant Heart Attack Randomized Trial (SADHART) Group. Sertraline treatment of major depression in patients with acute MI or unstable angina. JAMA 2002; 288: 701-709.

57 Berkman LF, Blumenthal J, Burg M, et al; Enhancing Recovery in Coronary Heart Disease Patients Investigators (ENRICHD). Effects of treating depression and low perceived social support on clinical events after myocardial infarction: the Enhancing Recovery in Coronary Heart Disease Patients (ENRICHD) randomized trial. JAMA 2003; 289: 3106-3116.

58 Lespérance F, Frasure-Smith N, Koszycki D, et al; CREATE Investigators. Effects of citalopram and interpersonal psychotherapy on depression in patients with coronary artery disease: the Canadian Cardiac Randomized Evaluation of Antidepressant and Psychotherapy Efficacy (CREATE) trial. JAMA 2007; 297 367-379.

59 Honig A, Kuyper AM, Schene AH, et al; MIND-IT investigators. Treatment of post-myocardial infarction depressive disorder: a randomized, placebocontrolled trial with mirtazapine. Psychosom Med 2007; 69: 606-613.

60 Witchell HJ, Hancox JC, Nutt DJ. Psychotropic drugs, cardiac arrhythmia and sudden death. J Clin Psychopharmacol 2003; 23: 58-77.

61 Cohen HW, Gibson G, Alderman MH. Excess risk of myocardial infarction in patients treated with antidepressant medications: association with use of tricyclic agents. Am J Med 2000; 108: 2-8.

62 Honkola J, Hookana E, Malinen S, et al. Psychotropic medications and the risk of sudden cardiac death during an acute coronary event. Eur Heart J 2012; 33: 745-751.

63 Mazza M, Lotrionte M, Biondi-Zoccai G et al. Selective serotonin reuptake inhibitors provide significant lower re-hospitalisation rates in patients recovering from acute coronary syndromes: evidence from a meta-analysis. J Psychopharmacol 2010; 24: 1785-1792.

64 Ekers D, Richards D, Gilbody S. A meta-analysis of randomized trials of behavioural treatment of depression. Psychol Med 2008; 38: 611-623.

65 de Mello MF, de Jesus Mari J, Bacaltchuk J, et al. A systematic review of research findings on the efficacy of interpersonal therapy for depressive disorders. Eur Arch Psychiatry Clin Neurosci 2005; 255: 75-82.

66 Freeland KE, Skala JA, Carney RM, et al. Treatment of depression after coronary artery bypass surgery: a randomized controlled trial. Arch Gen Psychiatry 2009; 66: 387-396.

67 Whalley B, Rees K, Davies P, et al. Psychological interventions for coronary heart disease. Cochrane Database Syst Rev 2011; (8): CD002902.

68 Rimer J, Dwan K, Lawlor DA, et al. Exercise for depression. Cochrane Database Syst Rev 2012; (7): CD004366.

69 Dunn AL, Trivedi MH, Kampert JB, et al. Exercise treatment for depression: efficacy and dose response. Am J Prev Med 2005; 28: 1-8.

70 Dunn AL, Trivedi MH, Kampert JB, et al. The DOSE Study: a clinical trial to examine efficacy and dose response of exercise as treatment for depression. Control Clin Trials 2002; 23: 584-603.

71 Blumenthal JA, Sherwood A, Babyak MA, et al. Exercise and pharmacological treatment of depressive symptoms in patients with coronary heart disease: Results from the UPBEAT (Understanding the Prognostic Benefits of Exercise and Antidepressant Therapy) study. J Am Coll Cardiol 2012; 60: 1053-1063.

72 Blumenthal JA, Babyak MA, O'Connor C, et al. Effects of exercise training on depressive symptoms in patients with chronic heart failure: The HF-ACTION randomized trial. JAMA 2012; 308: 465-474.

73 Freeman MP. Complementary and alternative medicine (CAM): considerations for the treatment of major depressive disorder. J Clin Psychiatry 2009; 70 Suppl 5: 4-6. 
74 Freeman MP, Fava M, Lake J, et al. Complementary and alternative medicine in major depressive disorder: the American Psychiatric Association Task Force report. J Clin Psychiatry 2010; 71: 669-681.

75 National Heart Foundation of Australia. Position statement. Fish fish oils, n-3 polyunsaturated fatty acids and cardiovascular health. Updated November 2008. http://www.heartfoundation.org.au/SiteCollectionDocuments/FishFishOils-position-statement.pdf (accessed Jun 2012).

76 Carney RM, Freedland KE, Rubin EH, et al. Omega-3 augmentation of sertraline in treatment of depression in patients with coronary heart disease: a randomized controlled trial. JAMA 2009; 302: 1651-1657.

77 Papakostas GI, Alpert JE, Fava M. S-adenosyl-methionine in depression: a comprehensive review of the literature. Curr Psychiatry Rep 2003; 5: 460-466.

78 Linde K, Berner MM, Kriston L. St John's wort for major depression. Cochrane Database Syst Rev 2008; (4): CD000448.

79 Nahas R, Sheikh 0. Complementary and alternative medicine for the treatment of major depressive disorder. Can Fam Physician 2011; 57: 659-663.

80 Gehi A, Haas D, Pipkin S, Whooley M. Depression and medication adherence in outpatients with coronary heart disease. Findings from the Heart and Soul Study. Arch Intern Med 2005; 165: 2508-2513.

81 Kronish I, Rieckmann N, Halm E, et al. Depressed patients are less likely to follow recommended risk reducing behaviors after acute coronary syndromes. J Gen Intern Med 2006; 21: 1178-1183.

82 DiMatteo MR, Lepper HS, Croghan TW. Depression is a risk factor for noncompliance with medical treatment: meta-analysis of the effects of anxiety and depression on patient adherence. Arch Intern Med 2000; 160 : 2101-2107.

83 Rieckmann N, Gerin W, Kronish IM, et al. Course of depressive symptoms and medication adherence after acute coronary syndromes: an electronic medication monitoring study. J Am Coll Cardiol 2006; 48: 2218-2222.

84 Glassman AH, Bigger JT, Gaffney M. Psychiatric characteristics associated with long-term mortality among 361 patients having an acute coronary syndrome and major depression: seven-year follow-up of SADHART participants. Arch Gen Psychiatry 2009; 66: 1022-1029.

85 Baver LK, Caro MA, Beach SR, et al. Effects of depression and anxiety improvement on adherence to medication and health behaviours in recently hospitalized cardiac patients. Am J Cardiol 2012; 109: 1266-1271.

86 Kronish IM, Rieckmann N, Burg MM, et al. The effect of enhanced depression care on adherence to risk-reducing behaviors after acute coronary syndromes: findings from the COPES trial. Am Heart J 2012; 164: 524-529.

87 Australian Institute of Health and Welfare (AlHW). Mental health services provided by general practitioners. http://mhsa.aihw.gov.au/services/generalpractice/ (accessed Feb 2013)

88 Stewart A, Driscoll A, Hare DL. National survey of Australian cardiologists' beliefs and practice regarding screening, diagnosis and management of depression. Heart Lung Circ 2009; 18 Suppl 3: S5.
89 Schrader G, Cheok F, Hordacre AL, Marker J. Predictors of depression 12 months after cardiac hospitalization: the Identifying Depression as a Comorbid Condition study. Aust N Z J Psychiatry 2006; 40: 1025-1030.

90 O'Neil A, Sanderson K, Oldenburg B, Taylor CB. Impact of depression treatment on mental and physical health-related quality of life of cardiac patients: a meta-analysis. J Cardiopulm Rehabil Prev 2011; 31: 146-156.

Appendix: Definition of National Health and Medical Research Council (NHMRC) grades of recommendations and evidence hierarchy*

\section{Definition of NHMRC grades of recommendations}

\section{Grade Description}

\begin{tabular}{|c|c|}
\hline A & Body of evidence can be trusted to guide practice \\
\hline B & Body of evidence can be trusted to guide practice in most situations \\
\hline C & $\begin{array}{l}\text { Body of evidence provides some support for recommendation(s) but care should be } \\
\text { taken in its application }\end{array}$ \\
\hline D & Body of evidence is weak and recommendation must be applied with caution \\
\hline \multicolumn{2}{|c|}{ NHMRC evidence hierarchy: designation of levels of evidence } \\
\hline Level & Intervention \\
\hline I & A systematic review of level II studies \\
\hline ॥ & A randomised controlled trial \\
\hline III-1 & A pseudorandomised controlled trial (ie, alternate allocation or some other method) \\
\hline III-2 & $\begin{array}{l}\text { A comparative study with concurrent controls: } \\
\text { Non-randomised, experimental trial } \\
\text { Cohort study } \\
\text { - Case-control study } \\
\text { - Interrupted time series with a control group }\end{array}$ \\
\hline III-3 & $\begin{array}{l}\text { A comparative study without concurrent controls: } \\
\text { Historical control study } \\
\text { - Two or more single arm study } \\
\text { - Interrupted time series without a parallel control group }\end{array}$ \\
\hline IV & Case series with either post-test or pre-test/post-test outcomes \\
\hline
\end{tabular}

* From NHMRC additional levels of evidence and grades for recommendations for developers of guidelines. ${ }^{2}$ 